\title{
A IMPORTÂNCIA DO BRINCAR NA EDUCAÇÃO INFANTIL
}

Carolline Rodrigues Guedes, Leonardo de Angelo Orlandi, Michele Dias Luccas, José Milton de Lima, Márcia Regina Canhoto de Lima

Universidade Estadual Paulista - FCT/UNESP. Curso de Educação Física, Presidente Prudente - SP. Curso de Pedadogia, Presidente Prudente - SP. CNPq/PIBIC. E-mail: carolguedes11@hotmail.com

\section{RESUMO}

Esta investigação tem como objeto de estudo e pesquisa a ludicidade no contexto da Educação Infantil. A pesquisa foi desenvolvida em duas salas de Educação Infantil: Pré I e II de uma instituição municipal, na cidade de Presidente Prudente, e contou com a participação de cinquenta e cinco crianças e duas educadoras. A investigação surgiu a partir da constatação de que alguns educadores desconhecem ou simplesmente ignoram a importância das Culturas da infância, principalmente do eixo ludicidade. O referencial teórico desta pesquisa é a Sociologia da Infância. A metodologia utilizada é de natureza qualitativa e caracteriza-se como pesquisa do tipo etnográfico. Os resultados coletados revelam que as educadoras compreendem a importância do brincar em sala de aula. Entretanto, é predominante, a desvalorização da ludicidade e imaginação dos alunos, por parte de algumas educadoras e um zelo excessivo pelo domínio da leitura e da escrita, nesta modalidade educacional.

Palavras-chave: Educação Infantil, Culturas da Infância, Sociologia da Infância, Ludicidade, Formação de professores.

\section{THE IMPORTANCE OF PLAY IN EARLY CHILDHOOD EDUCATION}

\begin{abstract}
This research has as object of study and research the playfulness in the context of early childhood education. The survey was developed in two rooms of early childhood education: Preschool I and II of a municipal institution, in the city of Presidente Prudente, and was attended by fifty-five children and two teachers. The investigation arose from the observation that some educators are unaware of or ignore the importance of childhood Cultures, mainly the axis playfulness. The theoretical framework of this research is the sociology of Childhood. The methodology used is qualitative in nature and is characterized as ethnographic type lookup. The collected results reveal that the educators understand the importance of play in the classroom. However, is prevalent, the devaluation of the playfulness and imagination of students, some educators and an excessive zeal for the field of reading and writing, this educational modality.

Keywords: Early childhood education, Cultures of childhood, Sociology of childhood, Playfulness, teacher training.
\end{abstract}




\section{INTRODUÇÃO}

O lúdico tem se apresentado como uma temática de destaque em congressos, encontros e eventos da área educacional, assim como o número de publicações relacionadas ao brincar também tem se intensificado. O crescimento acerca dessa temática deu-se pelo fato das contribuições que podem ocorrer no desenvolvimento cognitivo, motor e social da criança.

Neste sentido, esta pesquisa de Iniciação Científica - PIBIC/CNPQ (Conselho Nacional de Desenvolvimento Científico e Tecnológico) originou-se de um projeto de pesquisa maior, denominado "Um caminho para a infância: saindo de encruzilhadas no contexto da Educação Infantil", que foi desenvolvido em parceria com uma Instituição Municipal de Educação Infantil na cidade de Presidente Prudente, e é composto por docentes e discentes do curso de Pedagogia e Educação Física, da Faculdade de Ciências e Tecnologia - UNESP, Campus de Presidente Prudente, sendo todos integrantes do CEPELIJ - Centro de Estudos e Pesquisas em Educação, Ludicidade, Infância e Juventude e do Grupo de Pesquisa: "Cultura Corporal: saberes e fazeres", juntamente com a colaboração de educadores da instituição parceira.

Nesta pesquisa procuramos considerar a criança como sujeito cultural e social, assumindo a necessidade de investigar e ampliar a produção científica sobre a criança e as culturas da infância, pois Quinteiro, citado por Oliveira (2008, p. 2), aponta que "pouco se conhece sobre as culturas infantis porque pouco se ouve e pouco se pergunta às crianças [...] há ainda resistência em aceitar o testemunho infantil como fonte de pesquisa confiável e respeitável".

A pesquisa justifica-se ao possibilitar que discentes universitários, em processo de formação, e os educadores da instituição parceira, repensem suas práticas educativas e ampliem seus conhecimentos em relação à criança, que é produtora de cultura e possui características peculiares.

A partir disto, esta investigação assume como principais objetivos analisar como os professores concebem as Culturas da Infância e como eles trabalham um dos eixos estruturadores dessas culturas, a ludicidade.

\section{METODOLOGIA}

Esta pesquisa buscou primeiramente reconhecer as crianças como sujeitos capazes de produzir cultura, ao invés de tratá-las como simples objetos de pesquisa, e também ressaltar a importância da valorização do lúdico pelos professores no contexto da Educação Infantil, considerando a sua importância no desenvolvimento das crianças. Deste modo, foi autorizada pelo Comitê de Ética em Pesquisa com Seres Humanos processo n 102/2009. 
O presente trabalho é de natureza qualitativa, e de acordo com Prodanov e Freitas (2013, p. 70) "a utilização desse tipo de abordagem difere da abordagem quantitativa pelo fato de não utilizar dados estatísticos como o centro do processo de análise de um problema, não tendo, portanto, a prioridade de numerar ou medir unidades". Sendo assim, os dados que são coletados nessas pesquisas são descritivos, procurando retratar o mais fidedignamente possível a realidade estudada, preocupando-se muito mais com o processo do que com o produto.

Por pesquisa qualitativa entendemos qualquer tipo de pesquisa que gera resultados que não foram alcançados por procedimentos estatísticos ou outro tipo de quantificação. Pode referir-se a pesquisa sobre a vida das pessoas, histórias, comportamentos e também ao funcionamento organizativo, aos movimentos sociais ou às relações e interações. Alguns dos dados podem ser quantificados, porém, a análise em sim mesma é qualitativa (STRAUSS E CORBIN apud SANDÍN ESTEBAN, 2010, p. 124).

Pelo fato de a pesquisa qualitativa ser flexível, houve a necessidade de buscar novas formas de investigação, [...] "que partissem de outros pressupostos, rompessem com o antigo paradigma e sobretudo se adaptassem melhor ao objeto de estudo" (LÜDKE \& ANDRÉ apud VIÉGAS, 2007, p. 103). Para isso, selecionamos o procedimento técnico do tipo etnográfico.

A etnografia é um esquema de pesquisa desenvolvido pelos antropólogos para estudar a cultura e a sociedade. Etimologicamente etnografia significa "descrição cultural". Para os antropólogos o termo tem dois sentidos: (1) um conjunto de técnicas que eles usam para coletar dados sobre os valores, os hábitos, as crenças, as práticas e os comportamentos de um grupo social; e (2) um relato escrito resultante do emprego dessas técnicas (ANDRÉ, 1995, p. 27).

O estudo etnográfico possibilita um contato "face a face" com a realidade escolar. Por isso, André (1995) aponta que a etnografia permite que o pesquisador chegue bem perto da escola, entendendo seu cotidiano. Além disso, o pesquisador Marchi (2010, p. 194) diz que "a etnografia tem sido apontada como metodologia particularmente adequada ao imperativo de 'dar voz' às crianças fazendo-as participar na produção dos dados sociológicos sobre suas maneiras de ser, sentir, agir e pensar".

Nesse sentido, esta investigação contou com a participação de duas educadoras préescolares, cinquenta e cinco crianças, entre cinco e seis anos de idade, distribuídas nas turmas de Pré I e Pré II. As observações foram desenvolvidas às segundas-feiras na EMEI, no período das $13 \mathrm{~h} 00$ às $15 \mathrm{~h} 00$, com duração de sessenta minutos em cada grupo. As coletas dos dados aconteciam a partir da observação participante em que os dados foram escritos no diário de campo. Neste suporte, foram anotados procedimentos para facilitar o processo de sistematização 
de dados, dando destaque para a data da observação, a turma escolar, os nomes das crianças, o espaço de realização das atividades, a temática do brincar, os aspectos desenvolvidos, as ações realizadas pelos alunos e atores escolares durante as aulas e especialmente durante os momentos de brincadeira. Além da utilização de gravações e fotografias para dar mais fidedignidade aos dados.

Durante o período de observação também foi aplicado um questionário aberto às educadoras, com o intuito de [...] "aprofundar as questões e esclarecer os problemas observados" (ANDRÉ, 1995, p. 28).

Neste sentido, a pesquisa procurou, através das observações e questionários, identificar o olhar da instituição parceira para com as particularidades do Ensino Infantil e claramente compreender as dificuldades e limitações encontradas tanto pelas professoras, como pelas crianças no dia-a-dia no contexto educacional.

\section{RESULTADOS}

Durante as observações, procuramos conduzir nosso olhar para as ações que envolviam a "ludicidade" nos diferentes espaços escolares. Desta maneira, buscamos atentar-nos aos momentos em sala de aula e às atividades que propúnhamos para as crianças durante algumas aulas.

Nos primeiros dias de observação a professora Judite (nome fictício) participou ativamente com as crianças, já a professora Sara (nome fictício) não participou muito, mas ficava chamando a atenção dos alunos para que não conversassem e para que não corressem muito rápido para não se machucar.

No segundo dia de observação, as crianças nos receberam com bastante entusiasmo. Entramos na sala e perguntamos a elas como foi a semana, e uma criança respondeu: "- Esta semana a prô Judite fez as brincadeiras que vocês nos ensinaram na semana passada, foi muito legal!"

Através da fala da criança pudemos constatar que a professora repetiu as brincadeiras realizadas durante a intervenção passada. Neste dia de observação, a professora Judite levou vários brinquedos para a quadra poliesportiva, e proporcionou aos alunos a imaginação e a ludicidade de uma maneira bastante significativa, pois ela "entrou" nas brincadeiras dos alunos, dando-Ihes o prazer de brincar e aprender ao mesmo tempo.

Conforme as observações iam acontecendo, fomos percebendo a grande participação das crianças nas atividades desenvolvidas. Quando chegávamos à porta das salas, elas ficavam 
eufóricas, pois queriam brincar. Neste dia a Professora Sara nos disse: “- Eles perguntaram de vocês a semana inteira, queriam que chegasse logo a segunda feira, para encontrar com vocês!".

Em outra aula fizemos uma brincadeira em que as crianças deveriam fazer um círculo e ficar de pé com as mãos dadas. Nesse círculo eles iriam passar um bambolê pelo corpo sem soltar as mãos dos colegas. A professora Judite logo entrou no círculo para fazer a brincadeira também, e conforme acontecia a brincadeira, os alunos sentiam-se mais entusiasmados, pois a professora os ajudava e torcia para eles.

Conforme aconteciam as observações, era nítida a presença da professora Judite nas brincadeiras, pois ela participava e fazia parte das fantasias das crianças. Já a professora Sara não brincava com as crianças nas aulas, pois preferia ficar olhando de longe, chamando a atenção dos alunos para que não bagunçassem.

Enquanto fazíamos as observações, sentimos a necessidade de aplicar um questionário composto de cinco perguntas com as professoras, com o objetivo de analisar o que eles pensavam sobre o brincar na instituição.

Através das respostas do questionário percebemos que há uma grande preocupação por parte das professoras com o lúdico na escola, afirmando que é importante e que as crianças precisam disso. Porém, a professora Sara não saía muito nas aulas, o que contradiz muitas vezes o que ela escreve no questionário, ao contrário da professora Judite, que interagia e brincava muito com as crianças.

\section{DISCUSSÃO}

A presente pesquisa conta com uma ampla fundamentação teórica, já que esta base é de suma importância no caminhar dos estudos para entender as questões relacionadas às culturas da infância, em especial a ludicidade, no contexto escolar.

Deste modo, esta pesquisa tem como marco teórico a Sociologia da Infância, uma área do conhecimento que considera a criança como ator social pleno em seu desenvolvimento, um ser que produz culturas e é cheio de particularidades.

A Sociologia da Infância tem procurado incluir a criança no contexto social de modo que ela não se torne inferior ao adulto, mas que seja compreendida em suas particularidades. Assume, ainda, o desafio de pesquisar a infância em uma perspectiva interdisciplinar e reconhecer a criança em sua competência, participação, e protagonismo nas pesquisas, na educação, e em diferentes espaços sociais.

A criança é um ser humano também do hoje que não pode ser limitado ao 
amanhã, precisa ser compreendida a partir de si mesma e do seu próprio contexto. Representa um sujeito social, que não está passivo em seu processo de socialização, faz história e produz cultura. Esse reconhecimento de ator social ativo é um dos pressupostos básicos propostos pela Sociologia da Infância (LIMA; MOREIRA, 2014, p. 99-100).

Assim como os adultos precisam compreender as crianças, os educadores também fazem parte disso, pois muitos pensam que a escola é um lugar somente de socialização, e não levam em conta que ela pode e deve ser um espaço para o estímulo da criação e imaginação dos alunos (BRANCHER, 2008). As escolas de Educação Infantil precisam enriquecer a cultura lúdica com jogos e brincadeiras, acompanhados de brinquedos e um grande tempo para essa realização.

Dornelles (p. 107, 2001) diz:

Parece que tudo, na escola infantil, está sendo excessivamente pedagogizado, perdendo-se a ideia de prazer, que está inerente a cada atividade da criança. $\mathrm{O}$ prazer do brincar e esquecemos que: olhar, curtir, tocar, experimentar faz parte do ser criança, faz parte da descoberta na infância e da construção de novos sujeitos-criança.

Acredita-se que por meio do lúdico, a criança satisfaz suas necessidades, interesses e desejos particulares. Sendo assim, o lúdico é uma das maneiras mais eficazes de envolver os alunos nas atividades, pois a brincadeira é algo específico da criança. Silva e Sena (2010, p. 111), apontam que "[...] o brincar relaciona-se com o prazer. Se brincar é prazer, aprender brincando será um prazer para a criança".

Destarte, faz-se necessário que os professores tomem consciência da complexidade que é trabalhar no ambiente escolar, pois eles fazem parte da história de cada aluno.

Formar professores para introduzir o lúdico na escola, é um grande desafio, porém, é fundamental que o educador reconheça a riqueza da cultura lúdica infantil, e tenha consciência de que, brincando as crianças criam e recriam seu mundo imaginário, desenvolvendo a sua capacidade simbólica, a personalidade e a socialização.

\section{CONCLUSÃO}

O lúdico é uma atividade indispensável no contexto da Educação Infantil, pois o professor pode utilizá-lo para alcançar os melhores resultados no processo de ensino-aprendizagem e desenvolvimento infantil. Porém, este campo ainda precisa de muita investigação, pois é fundamental para o desenvolvimento da criança, apesar de ser pouco valorizado e utilizado no contexto escolar. 
Através da brincadeira, o professor pode se aproximar mais da criança, tornando seus momentos um meio de comunicação, recreação e prazer, desenvolvendo valores morais, éticos, sociais e cognitivos, possibilitando a construção de conhecimentos.

É fundamental que o professor considere toda riqueza da cultura lúdica infantil e todo contexto que ela traz consigo para a escola. Faz-se necessário também, que as professoras aprofundem seus conhecimentos e enriqueçam as experiências lúdicas das crianças no contexto da Educação Infantil para que, assim, elas atinjam seu desenvolvimento pleno de modo eficaz.

A partir do que foi demonstrado nesta pesquisa, esperamos ter contribuído para a produção de saberes e pretendemos continuar os estudos, tendo em vista a necessidade de avançar na produção científica em relação à temática e à importância da ludicidade na vida humana, em especial no desenvolvimento de nossas crianças, pois percebemos que ver e ouvir a criança é uma condição necessária em qualquer pesquisa que deseja estudar a infância e suas culturas.

\section{REFERENCIAS}

ANDRÉ, M. E. D. A. Etnografia da prática escolar. 17. ed. Campinas: Papirus, 1995.

BRANCHER, V. R. Cultura Infantil: problematizando a ludicidade e o ser criança hoje, 2008.

DORNELLES, L. V. Na escola infantil todo mundo brinca se você brinca. In: CRAIDY, C. M.; KAERCHER, G. E. P. S. (Org). Educação Infantil: pra que te quero? Porto Alegre: Artmed, 2001.

LIMA, J. M.; MOREIRA, T. A.; LIMA, M. R. C. A sociologia da infância e a educação infantil: outro olhar para as crianças e suas culturas. Rev. Contrapontos, v 14, n. 1, p. 95-110, 2014.

MARCHI, R. C. O "ofício de aluno" e o "ofício de criança": articulações entre a sociologia da educação e a sociologia da infância. Rev. Portuguesa de Educação, v. 23, n.1, p. 183-202 2010.

OLIVEIRA, F. Sociologia da Infância. Rev. Sociologia. Disponível em: <http://sociologiacienciaevida.uol.com.br/ESSO/Edicoes/17/artigo92128-2.asp>. Acesso em: 09 jan. 2014.

PRODANOV, C. C.; FREITAS, E. C. Metodologia do trabalho científico: métodos e técnicas da pesquisa e do trabalho acadêmico. 2a Ed, Novo Hamburgo: Feevale, 2013.

SANDÍN ESTEBAN, P. P. Pesquisa qualitativa em educação: fundamentos e tradições. Porto Alegre: AMGH, 2010.

SILVA, J. A.; SENA, S. S. A importância do lúdico na Educação Infantil: fundamentação teórica. Caderno Multidisciplinar de Pós - Graduação da UCP. Pitanga, v.1, n.1, p. 106-121, jan 2010. 
VIÉGAS, L. S. Reflexões sobre a pesquisa etnográfica em Psicologia e Educação. Salvador, jan/junho 2007. 